\author{
Janusz LEWANDOWSKI ${ }^{1}$ \\ Dariusz ROZUMEK ${ }^{2}$
}

\title{
OCENA STOPNIA ZUŻYCIA ZESPOŁU WENTYLATORA NA PODSTAWIE POMIARU I ANALIZY DRGAŃ LOŻYSK
}

\begin{abstract}
W pracy omówione zostały wybrane metody pomiarów drgań maszyn wirujących (silników, wirników wentylatorów, przekładni mechanicznych, itp.) zastosowanych do oceny stanu maszyn pracujących w warunkach przemysłowych. Przedstawiono zastosowaną aparaturę badawczą pozwalającą na zebranie danych do analizy. Na przykładzie pomiarów drgań łożysk wentylatora promieniowego typu WPK-3,9 pracującego w stacjach wentylatorów głównych w przemyśle górniczym przedstawiono analizę drgań, dzięki której określono stan techniczny wirujących części wentylatora.
\end{abstract}

Słowa kluczowe: diagnostyka maszyn, drgania, łożyska, wirnik, wentylatory, przekładnie mechaniczne

\section{Wprowadzenie}

Drgania układów fizycznych są zjawiskiem powszechnie występującym w przyrodzie. Oddziaływanie drgań może być pozytywne (młoty udarowe, utrząsarki, zagęszczarki, itp.) oraz negatywne (drgania maszyn wirnikowych, wentylatory, przekładnie sprężarki, itp.) [1,2]. Negatywny wpływ drgań maszyn wirujących pracujących w przemyśle często prowadzi do występowania stanów awaryjnych, uszkodzeń części maszyn skutkujących postojami, przedwczesnymi remontami. $Z$ ekonomicznego punktu widzenia dąży się do tego aby eksploatacja maszyn odbywała się w sposób bezawaryjny. Świadomy użytkownik zdaje sobie sprawę, że elementy maszyn z czasem ulegają naturalnemu zużyciu. $\mathrm{Z}$ tego powodu prowadzone są okresowe kontrole, przeglądy, badania i pomiary pracujących elementów maszyn w różnych zakresach.

\footnotetext{
${ }^{1}$ Autor do korespondencji / corresponding author: Janusz Lewandowski, Politechnika Opolska, Katedra Mechaniki i PKM, ul. Mikołajczyka 5, 45-271 Opole; Ośrodek Pomiarów i Automatyki Przemysłu Węglowego S.A., ul. Hagera 14A, 41-800 Zabrze, tel. 604585204; jansuz210@wp.pl

2 Dariusz Rozumek, Politechnika Opolska, Katedra Mechaniki i PKM, ul. Mikołajczyka 5, 45-271 Opole; tel. 774498410; d.rozumek@ po.opole.pl
} 
Celem pracy jest przedstawienie wyników okresowo prowadzonych pomiarów drgań łożysk wentylatora typu WPK-3,9 wraz z jego oceną stanu technicznego.

\section{Opis procedury badawczej}

\subsection{Aparatura do pomiarów drgań}

Przedstawione badania drgań maszyn prowadzono $\mathrm{z}$ wykorzystaniem dwóch rodzajów urządzeń pozwalających na zebranie niezbędnych do oceny danych. Pierwsze zastosowano przenośne urządzenie (Vibrotip firmy Pruftechnik pokazany na rys. 1) umożliwiające prowadzenie pomiarów ogólnego poziomu drgań. Pomiary tego typu prowadzone są okresowo lub w sposób ciągły. Polegają one na szerokopasmowym pomiarze drgań łożysk (w zakresie 4 - 10000 $\mathrm{Hz}$ ) i śledzeniu trendów zmian poziomu drgań w dłuższym okresie czasu (np. miesiąc, rok).

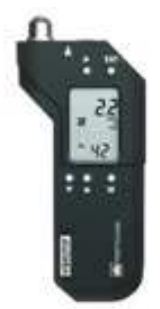

Rys. 1. Ręczne urządzenie pomiarowe do drgań Vibrotip firmy Pruftechnik [3]

Fig. 1. Manually measuring device to vibrate Vibrotip company Pruftechnik [3]

Wielkościami mierzonymi są prędkości drgań. Dla jednego węzła pomiarowego otrzymuje się trzy wartości liczbowe wynikające z kierunków dokonywania pomiaru (rys. 2), mianowicie:

- H (horizontal "x") - czujnik pomiarowy ustawiony w kierunku poziomym,

- V (vartical "y") - czujnik pomiarowy ustawiony w kierunku pionowym,

- A (axial "z") - czujnik pomiarowy ustawiony w osi.

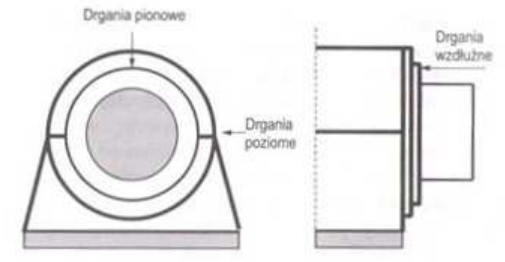

Rys. 2. Kierunki pomiaru drgań w węzłach łożyskowych [4]

Fig. 2. Directions vibration measurement in bearing nodes [4] 
Miarą wielkości drgań pozwalającą na obiektywną ocenę jest wartość skuteczna prędkości drgań $\mathrm{V}_{\mathrm{RMS}}$ (root mean square). Wartość ta zdefiniowana jest następująco [5]

$$
v_{R M S}=\sqrt{\frac{1}{T} \int_{0}^{T} v^{2}(t) d t}
$$

gdzie: $v(\mathrm{t})$ - prędkość drgań zależna od czasu,

VRMS - odpowiednia wartość średniokwadratowa prędkości,

$\mathrm{T}$ - przedział czasu uwzględniany w analizie.

Z otrzymanych wyników drgań buduje się wykres, który pozwala dokonać oceny stanu technicznego wirującego urządzenia oraz zgodnie z zaleceniami producenta wybrać optymalny moment na przeprowadzenie remontu (rys. 3).

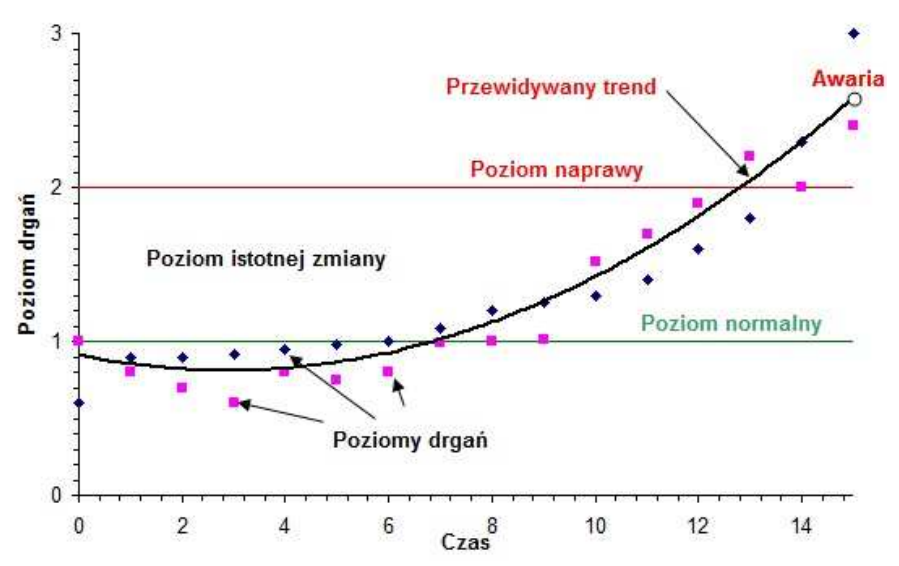

Rys. 3. Wykres z wynikami szerokopasmowego pomiaru drgań

Fig. 3. Chart results broadband vibration measurement

Inne, bardziej skomplikowane urządzenia pomiarowe pozwalają na wykonywanie badań w szerokim zakresie, między innymi: pomiarze przemieszczeń, prędkości, przyspieszeń, analizy częstotliwościowej, itp. Na rynku dostępnych jest wiele urządzeń tzw. analizatorów drgań. Poza nimi często wykorzystywane są wszelkiego rodzaju przystawki lub karty pomiarowe (np. National Instruments), dzięki którym możliwe jest budowanie systemów pomiarowych dostosowanych do aktualnych potrzeb badawczych. Rejestrowane drgania poddaje się obróbce korzystając z oprogramowania matematycznego (np. Matlab). Wynikami prowadzenia tego rodzaju badań i obliczeń są wykresy drgań w trzech płaszczyznach (H, V, A) oraz ich widma częstotliwościowe. Mając te dane i uwzględniając budowę danego urządzenia (a zatem znając częstotliwości cha- 
rakterystyczne poszczególnych elementów) możliwa jest ocena stopnia zużycia pracujących elementów. W niniejszej pracy, jako kolejne urządzenie pomiarowe zastosowano czterokanałową kartę pomiarową National Instruments NI9234 wraz z trzema przetwornikami przyspieszeń IMI601A01. Kompletny zestaw połączono z komputerem z zainstalowanym oprogramowaniem LabView (rys. 4 i 5).

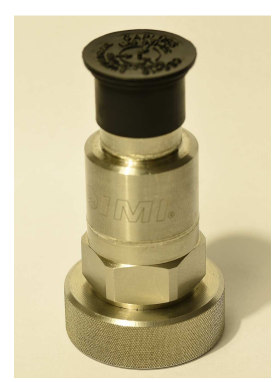

Rys. 4. Czujnik drgań IMI601A01

Fig. 4. Vibration sensors IMI601A0

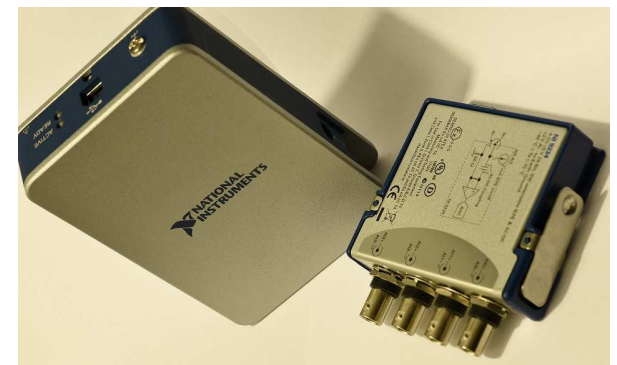

Rys. 5. Karta pomiarowa NI9234

Fig. 5. Measuring card NI9234

\subsection{Badany obiekt}

Badaniu poddano wentylator promieniowy typu WPK 3,9 pracujący w stacji wentylatorów głównych zakładu górniczego. Na rys. 6 pokazano badany wentylator wraz z napędem bez widocznego wirnika. W tabeli 1 zestawiono podstawowe parametry techniczne.

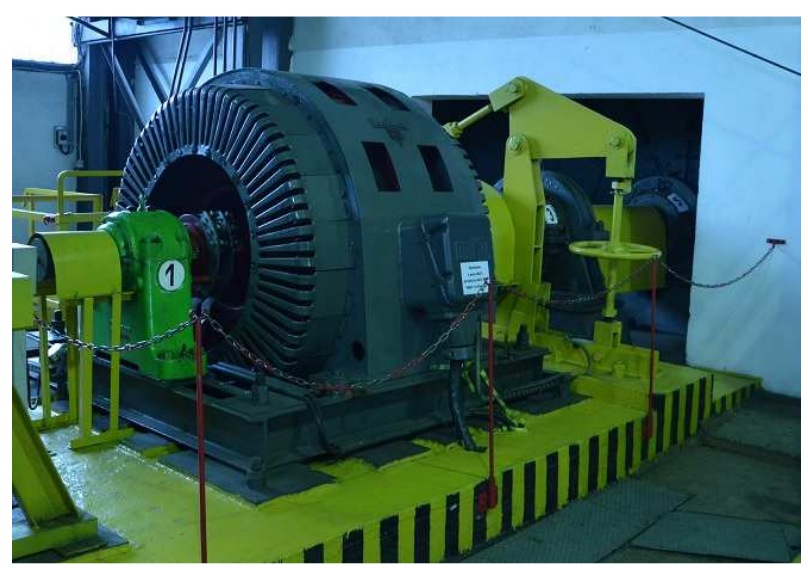

Rys. 6. Wentylator promieniowy typu WPK 3,9

Fig. 6. Radial ventilator type WPK 3.9 
Tabela 1. Dane techniczne wentylatora typu WPK 3,9

Table 1. Technical data ventilator type WPK 3.9

\begin{tabular}{|c|c|c|c|c|c|c|}
\hline $\begin{array}{c}\text { Średnia wirnika, } \\
\mathrm{mm}\end{array}$ & $\begin{array}{c}\text { Prędkość } \\
\text { obrotowa, } \\
\text { obr/min }\end{array}$ & $\begin{array}{c}\text { Wydajność, } \\
\mathrm{m}^{3} \mathrm{~s}\end{array}$ & $\begin{array}{c}\text { Spiętrzenie } \\
\text { całkowite, Pa }\end{array}$ & $\begin{array}{c}\text { Spraw- } \\
\text { ność }\end{array}$ & $\begin{array}{c}\text { Moc, } \\
\mathrm{kW}\end{array}$ & $\begin{array}{c}\text { Masa bez } \\
\text { silnika, } \mathrm{kg}\end{array}$ \\
\hline 3900 & 500 & 250 & 4400 & 0,86 & 1279 & 25770 \\
\hline
\end{tabular}

Pomiary wykonano w węzłach łożyskowych, w trzech płaszczyznach mocując czujniki drgań za pośrednictwem magnesów stałych.

\subsection{Metodyka badań}

W przypadku szerokopasmowych drgań (Vibrotip) pomiar polegał na przykładaniu czujnika, z podkładką magnetyczną, w określonych miejscach na obudowach łożysk i rejestracji wartości drgań. $Z$ otrzymanych danych sporządzono wykresy trendów zmian poziomu drgań. W przypadku pomiarów drgań z zastosowaniem karty pomiarowej z trzema czujnikami drgań zarejestrowany sygnał poddawany jest obróbce. W pierwszej kolejności z sygnału wybierany był jego fragment o długości trwającej dokładnie jedną sekundę. Znając częstotliwość rejestracji sygnału, która wynosiła $25,6 \mathrm{kHz}$ znana była również liczba próbek brana do analizy tj. 25600 próbek oraz odstęp czasu pomiędzy kolejnymi próbkami tj. 3,90625 $10^{-05} \mathrm{~s}$. Wyznaczone dane pomiarowe pozwoliły na przeprowadzenie analizy częstotliwościowej za pomocą szybkiej transformaty Fouriera (FFT). Obliczenia wykonano w programie Matlab. W uzyskanych wynikach widma częstotliwości poszukiwano prążków o częstotliwościach charakterystycznych dla danych uszkodzeń maszyny. W opisywanym przypadku poszukiwano częstotliwości związanych z $[4,5]$ :

- niewyważeniem wału (ekscentrycznością wału),

- z luzem mechanicznym, $\quad f=\frac{1}{3} \cdot f_{o b r}, \quad f=\frac{1}{2} \cdot f_{o b r}, f=2 \cdot f_{o b r}$

- wywołane ruchem łopat wentylatora. $f=l_{w} \cdot f_{o b r}$

Dodatkowo z uwagi na fakt, że wirnik zamocowany jest na końcu wału poza łożyskowaniem (wirnik przewieszony) zwracano uwagę na drgania spowodowane ugięciem wału objawiające się drganiami promieniowymi współfazowymi oraz drganiami osiowymi przeciwfazowymi.

Przed rozpoczęciem analizy zarejestrowanych drgań wykonano sprawdzenie poprawności obliczeń poprzez podstawienie wygenerowanych danych ze znanego przebiegu ruchu. $\mathrm{tj}$.:

$y(t)=2 \cdot \sin (2 \pi \cdot 150 \cdot t)+6 \cdot \sin (2 \pi \cdot 600 \cdot t)+0,6 \cdot \sin (2 \pi \cdot 230 \cdot t)$

Wynik przedstawiono na rys. 7. 

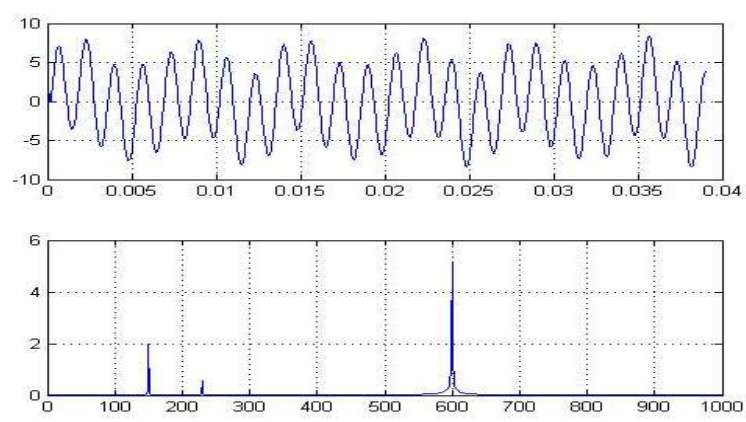

Rys. 7. Wyniki pomiarów wynik analizy znanego ruchu

Fig. 7. The results of the measurement result of the analysis of the well-known motion

Ruch ten złożony był z trzech ruchów o częstotliwościach 150, 600, $230 \mathrm{~Hz}$ oraz wartościach amplitud 2, 6, 0,7 m. Częstotliwość próbkowania była taka sama jak w pomiarze drgań wentylatora. Otrzymane wyniki potwierdziły prawidłowo przyjęte założenia obliczeń.

\section{Wyniki badań $i$ ich analiza}

Wyniki pomiarów szerokopasmowego poziomu prędkości drgań dla łożyska 34 i 5 pokazano na rys. 8. Pomiary wykonane zostały w okresie od czerwca 2014 do lutego 2017 r. w dwumiesięcznych odstępach czasu.

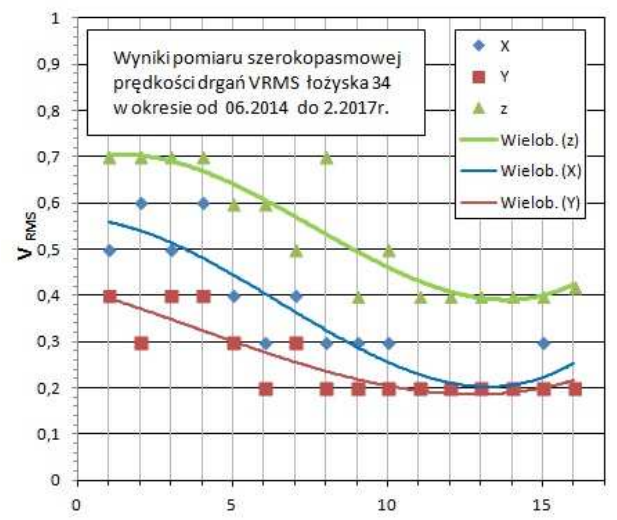

b)

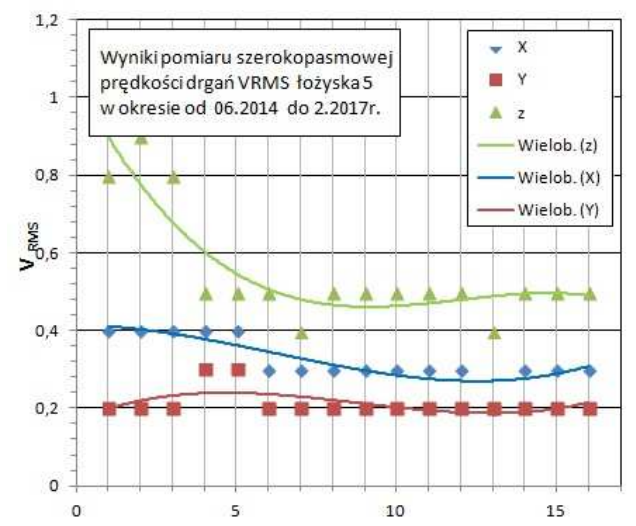

Rys. 8. Wyniki pomiarów prędkości drgań łożysk (VRMs mm/s): a) 34, b) 5

Fig. 8 . The speed measurements of vibration bearings ( $\mathrm{V}_{\mathrm{RMS}} \mathrm{mm} / \mathrm{s}$ ): a) 34 , b) 5 
Oceny dokonano według kryteriów dla określonych grup maszyn opisanych w załączniku B w normie [6]. Tabela 2 przedstawia graniczne strefy intensywności drgań przyjęte do oceny. $Z$ danych przedstawionych na rys. 8 wynika, że aktualne wartości drgań łożyska $34 \mathrm{w}$ kierunku x wynoszą $0,2 \mathrm{~mm} / \mathrm{s}$, w kierunku y $0,2 \mathrm{~mm} / \mathrm{s}$, a w kierunku z $0,42 \mathrm{~mm} / \mathrm{s}$.

Tabela 2. Graniczne strefy intensywności drgań przyjęte do oceny

Table 2. Border zone vibration intensity accepted for evaluation

\begin{tabular}{|c|c|c|}
\hline Ocena & $\begin{array}{c}\text { Średniokwadratowa } \\
\text { wartość prędkości } \\
\text { drgań, mm/s }\end{array}$ & Klasa III \\
\hline Dobry & 1,8 & A \\
\hline Nadający się & 4,5 & B \\
\hline Dopuszczalny & 11,2 & $\mathrm{C}$ \\
\hline Niedopuszczalny & 45 & $\mathrm{D}$ \\
\hline
\end{tabular}

Drgania łożyska $5 \mathrm{w}$ kierunku x wynoszą $0,3 \mathrm{~mm} / \mathrm{s}$, w kierunku y $0,2 \mathrm{~mm} / \mathrm{s}$, a w kierunku z $0,5 \mathrm{~mm} / \mathrm{s}$. Wartości drgań nie są duże i na podstawie przyjętych kryteriów (stref granicznych) stan techniczny w badanym zakresie ocenia się jako dobry. Wyniki pomiarów drgań łożysk 34 i 5, z zastosowaniem karty pomiarowej NI9234, przedstawiono na rys. 9 i 10. W wynikach widm częstotliwościowych można zaobserwować występowanie spodziewanych charakterystycznych prążków częstotliwości takich jak: $9 \mathrm{~Hz}$ dotyczących niewyważenia wirnika widoczne głównie na wykresach w kierunkach x i y oraz $90 \mathrm{~Hz}$ wywołane ruchem łopat wentylatora widoczne na wszystkich wykresach. Porównując wyniki z rys. 9 i 10 można zauważyć największe wartości amplitud przyspieszeń występujące w kierunku z, a najniższe w kierunku y dla zakresu 0 do $110 \mathrm{~Hz}$. Natomiast dla zakresu 110 do $220 \mathrm{~Hz}$ na rys. 9 obserwuje się podobną tendencję jak opisano wyżej, a na rys. 10 największe wartości amplitud przyspieszeń występują w kierunku x. Analizując dalsze częstotliwości obserwuje się nieznaczne fluktuacje. Większe wartości drgań w kierunku z są prawdopodobnie związane z przewieszoną konstrukcją wentylatora (wirnik na końcu wału poza łożyskowaniem). Biorąc pod uwagę wyniki pomiarów drgań z metody szerokopasmowej oraz analizy widm częstotliwościowych można stwierdzić, że badane urządzenie generuje drgania o spodziewanych częstotliwościach ale wartości tych drgań nie są wysokie. 
a)
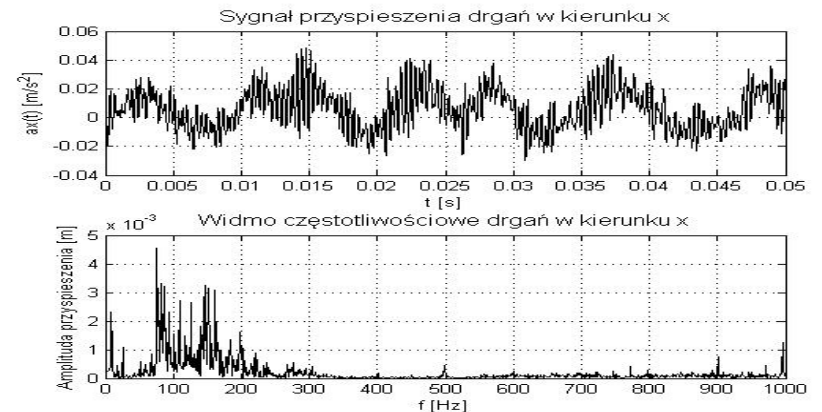

b)
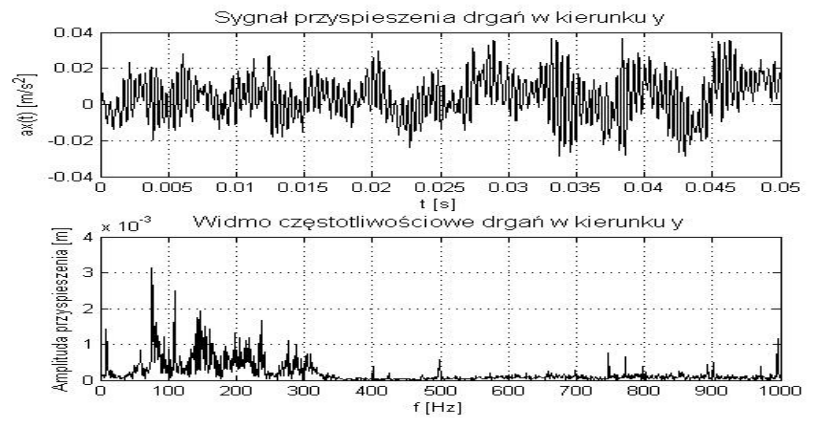

c)
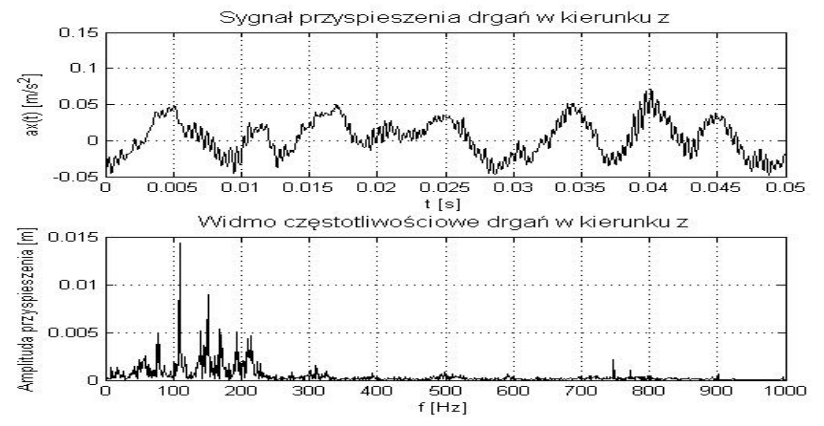

d)

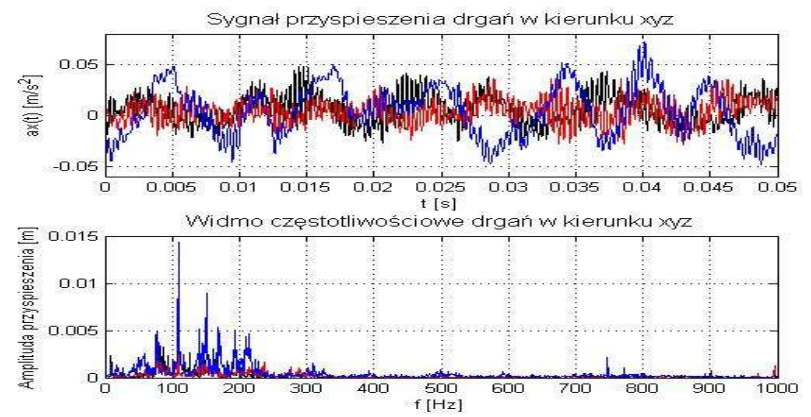

Rys. 9. Wyniki pomiarów drgań łożyska $34\left(\mathrm{~m} / \mathrm{s}^{2}\right)$ : a) kierunek $\left.\mathrm{x}, \mathrm{b}\right)$ kierunek y, c) kierunek z, d) zestawienie dla kierunków xyz

Fig. 9. The results of measurements of vibration of the bearing $34\left(\mathrm{~m} / \mathrm{s}^{2}\right)$ : a) $x$ direction, $b$ ) y direction $y, c) z$ direction, d) summary for directions of the xyz 
a)
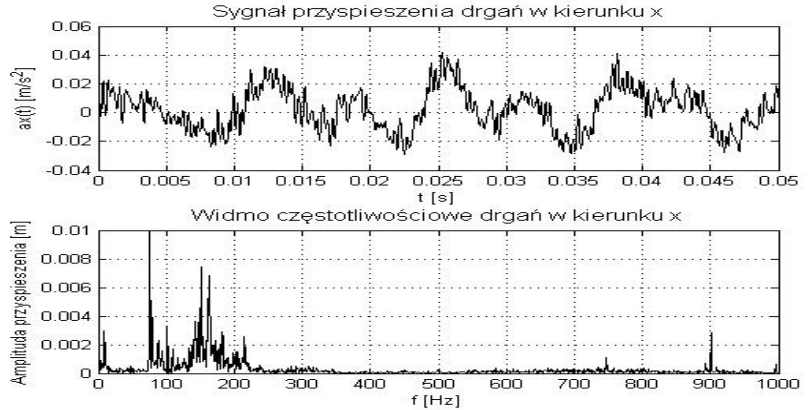

b)

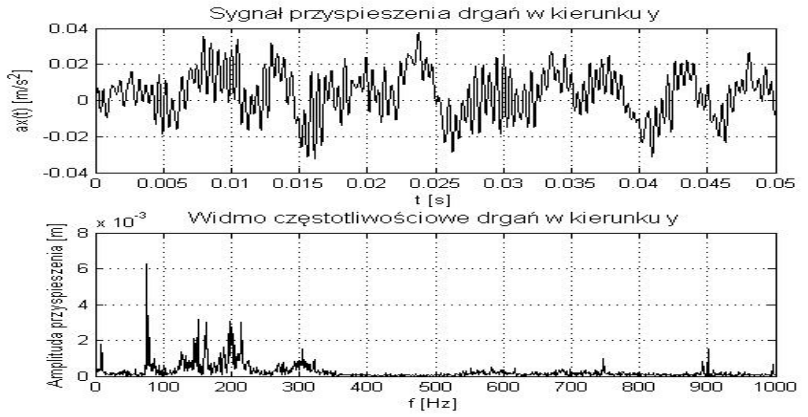

c)
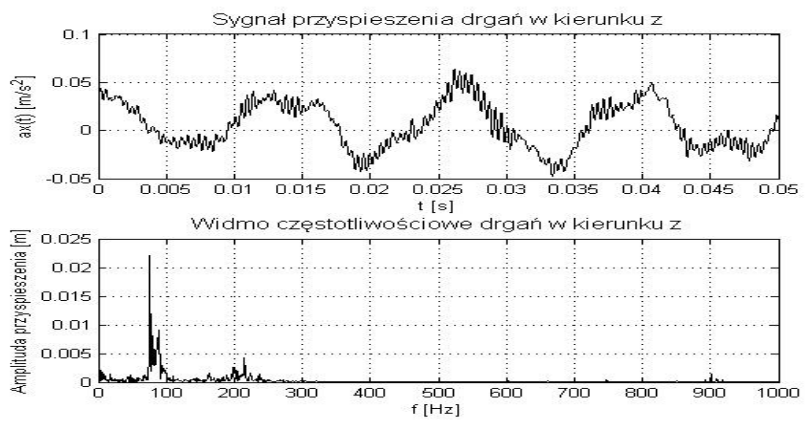

d)
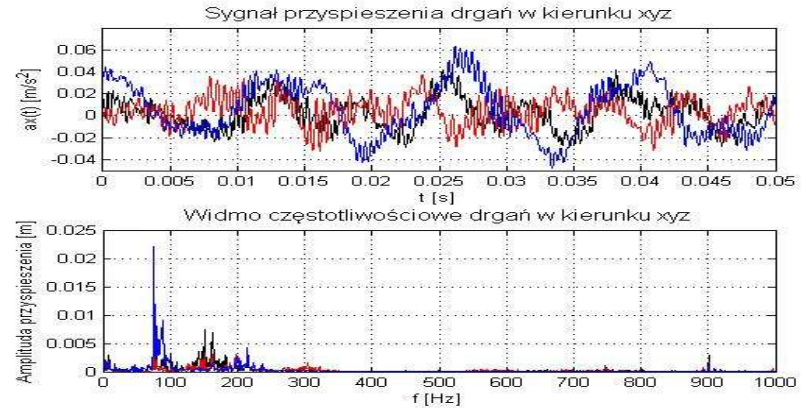

Rys. 10. Wyniki pomiarów drgań łożyska $5\left(\mathrm{~m} / \mathrm{s}^{2}\right)$ : a) kierunek $\mathrm{x}$, b) kierunek y, c) kierunek z, d) zestawienie dla kierunków xyz

Fig. 10. The results of measurements of vibration of the bearing $5\left(\mathrm{~m} / \mathrm{s}^{2}\right)$ : a) $x$ direction, $b$ ) y direction $y, c) z$ direction, d) summary for directions of the xyz 


\section{Wnioski}

W pracy przedstawiono:

- Szerokopasmowy pomiar prędkości drgań, który pozwala ocenić zużycie wentylatora oraz zaplanować wykonanie remontu w dogodnym czasie.

- Pomiar widma częstotliwości, który daje więcej informacji w porównaniu z pomiarem szerokopasmowym drgań. Umożliwia określenie powodu wzrostu wartości drgań na podstawie charakterystycznych częstotliwości pracujących i ulegających zużyciu elementów urządzenia.

- Zastosowanie kart pomiarowych oraz oprogramowania (LabView, Matlab) umożliwiających dostosowanie systemu pomiarowego do specyficznych warunków pracy różnych urządzeń jak i wymagań zleceniodawcy.

- Zmierzone wartości drgań wentylatora i zaprezentowane wyniki, które nie są wartościami wysokimi mogącymi wywołać stany awaryjne. Wentylator ten należy do grupy ważnych urządzeń (zapewniający powietrze w wyrobiskach górniczych), z tego też powodu nie dopuszcza się do uszkodzenia wirnika.

\section{Literatura}

[1] Kucharski T.: Drgania mechaniczne Rozwiązywanie zagadnień z Mathcad-em, Wydawnictwo Naukowo-Techniczne, Warszawa, 2004.

[2] Lewandowski J., Jakubowski J., Rozumek D.: Wpływ drgań naczyń wyciągowych na przebieg hamowania bezpieczeństwa maszyny wyciągowej, Przeg. Górniczy 6, 2016.

[3] http://www.pruftechnik.com.pl, dostęp styczeń 2017.

[4] Dwojak J., Rzepiela M.: Diagnostyka drganiowa stanu maszyn i urządzeń, Biuro Gamma, Warszawa, 2004.

[5] Cempel Cz.: Wibroakustyka stosowana, PWN, Warszawa, 1989.

[6] PN-ISO 10816-1, Drgania mechaniczne, Ocena drgań maszyn na podstawie pomiarów na częściach niewirujących, Wytyczne ogólne, PKN, 1998.

\section{ASSESSMENT OF THE DEGREE OF FAN CONSUMPTION BASED MEASUREMENT AND ANALYSIS OF BEARING VIBRATIONS}

\section{S u m m a r y}

The work presents selected methods of vibration measurement of rotating machines (motors, fan rotors, mechanical gears, etc.) used to evaluate the condition of machines operating in industrial conditions. Presented research apparatus used to record data for analysis. Based on measurements of the vibrations of radial fan bearings type WPK-3.9 operating in mining factory a vibration analysis was presented, which determined the technical condition of the fan.

Keywords: machine diagnostics, vibration, bearings, rotor, fans, gear 